\title{
Effects of method of dehydration on post exercise rehydration
}

\author{
D. T. Archer \\ Faculty of Applied Sciences, University of Sunderland, Sunderland SR1 3SD, UK
}

The American College of Sports Medicine guidelines on post exercise fluid replacement are based on studies that used exercise to induce hypohydration $^{(1)}$. However, other rapid weight loss practices such as fluid restriction are frequently adopted by athletes in weightcategorised sports to dehydrate prior to competition ${ }^{(2)}$. The aim of the present study was to assess whether the method of dehydration would affect subsequent post exercise rehydration.

Twelve recreationally active male subjects either remained euhydrated (EU), or reduced their body mass by $2.0 \%$ by $24 \mathrm{~h}$ fluid restriction (FR), or a combination of intermittent exercise in the heat $\left(34^{\circ} \mathrm{C}, 60 \% \mathrm{rh}\right)$ followed by $13 \mathrm{~h}$ fluid restriction $(\mathrm{FREX}) .30 \mathrm{~min}$ post performance of a maximal exercise capacity test, they ingested 2428 (SD 561) $\mathrm{ml}$ (equivalent to $150 \%$ of their total body mass loss ${ }^{(3)}$ ) of a carbohydrate electrolyte drink $\left(6 \%\right.$ carbohydrate and $\left.21 \mathrm{mM}\left[\mathrm{Na}^{+}\right]\right)$over a $60 \mathrm{~min}$ period. Blood and urine samples were collected prior to dehydration, pre and post exercise capacity test and every hour during the 60 min rehydration and $4 \mathrm{~h}$ recovery phase. Subject's completely emptied their bladders at each time point. Data were analysed using repeated measures ANOVA and are presented as mean (SD).

\begin{tabular}{|c|c|c|c|c|c|c|}
\hline & \multicolumn{2}{|c|}{ EU trial } & \multicolumn{2}{|c|}{ FR trial } & \multicolumn{2}{|c|}{ FREX trial } \\
\hline & Mean & SD & Mean & $\mathrm{SD}$ & Mean & $\mathrm{SD}$ \\
\hline Total urine volume $(\mathrm{ml})$ & $1997 *$ & 631 & 1294 & 685 & 1306 & 420 \\
\hline Final net fluid balance $(\mathrm{ml})$ & $+150^{*}$ & 490 & -495 & 253 & -563 & 165 \\
\hline Overall drink retention (\%) & $19 *$ & 21 & 50 & 16 & 46 & 13 \\
\hline
\end{tabular}

*Denotes significantly different from FR and FREX trials $(P<0.05), n=12$.

The calculated decrease in plasma volume prior to the start of drinking was greater in the FREX trial -6.8 (SD 3.5 ) \% compared with the FR trial -2.8 (SD 4.9) \%. Urinary potassium excretion during the recovery period was significantly greater in the FREX trial 35.1 (SD 22.5) mmol, compared with the FR trial 19.3 (SD 6.2) mmol. Serum osmolality and sodium concentration did not differ between the FR and FREX trials. Total urine volumes produced, overall drink retention and net fluid balance were significantly different in the EU trial compared with the FR and FREX trials, but did not differ between the FR and FREX trials.

In conclusion, hypohydration induced by two methods of dehydration resulted in differing body fluid and electrolyte losses during the dehydration and rehydration phases, but did not influence post-exercise retention of a carbohydrate electrolyte drink.

1. Sawka MN, Burke LM, Eichner RE et al. (2007) Med Sci Sports Exerc 39, 377-390.

2. Artioli GG, Gualano B, Franchini E et al. (2010) Med Sci Sports Exerc 42, 436-442.

3. Shirreffs SM, Taylor AJ, Leiper JB et al. (1996) Med Sci Sports Exerc 28, 1260-1271. 